\title{
Comparative Studies on Bioactive Constituents in Hawk Tea Infusions with Different Maturity Degree and Their Antioxidant Activities
}

\author{
Ming Yuan, ${ }^{1}$ Xuejing Jia, ${ }^{1}$ Chunbang Ding, ${ }^{1}$ Shu Yuan, ${ }^{2}$ \\ Zhongwei Zhang, ${ }^{2}$ and Yanger Chen ${ }^{1}$ \\ ${ }^{1}$ College of Life Sciences, Sichuan Agricultural University, Ya'an 625014, China \\ ${ }^{2}$ College of Resources and Environmental Science, Sichuan Agricultural University, Chengdu 611100, China
}

Correspondence should be addressed to Ming Yuan; yuanmingsicau@126.com

Received 9 January 2014; Revised 22 June 2014; Accepted 24 June 2014; Published 15 July 2014

Academic Editor: Luisa M. Sandalio

Copyright (C) 2014 Ming Yuan et al. This is an open access article distributed under the Creative Commons Attribution License, which permits unrestricted use, distribution, and reproduction in any medium, provided the original work is properly cited.

\begin{abstract}
Hawk tea (Litsea coreana var. lanuginose) is a very popular herbal tea in the southwest of China. According to the maturity degree of raw materials, Hawk tea can usually be divided into three types: Hawk bud tea (HB), Hawk primary leaf tea (HP), and Hawk mature leaf tea (HM). In this study, some of the bioactive constituents and antioxidant properties of the three kinds of Hawk tea infusions were comparatively investigated. The results showed that the contents of total flavonoids, vitamin $\mathrm{C}$, and carbohydrates in Hawk bud tea infusion (HBI) were higher than those in Hawk primary leaf tea infusion (HPI) and Hawk mature leaf tea infusion (HMI). HPI had higher contents of total polyphenols and exhibited better DPPH radical scavenging activity and ferric reducing activity power. HBI could provide more effective protection against erythrocyte hemolysis. As age is going from bud to mature leaf, the ability to inhibit the formation of low density lipoprotein (LDL) conjugated diene and the loss of tryptophan fluorescence decreased. The bioactive constituents and antioxidant activities of Hawk tea infusions were significantly affected by the maturity degree of the raw material.
\end{abstract}

\section{Introduction}

Generally, the production and scavenging of free radicals keep dynamic balance in human body. However, massive free radicals can be generated in cellular metabolic process under the stress condition [1]. And excessive free radicals can induce damages to cells or tissues and destroy the structure and function of biological macromolecules, which can cause various diseases [2]. Fortunately, the antioxidants can help cells keep the normal metabolic system in face of excessive free radicals. In recent years, herbal tea steps into the public eyes because of its high antioxidant activity and other health benefits [3]. There are a mass of flavones or other polyphenols in herbal tea. It was reported that phenolic compounds could reduce the risk of cardiovascular disease or cancer, which might be related to their antioxidant activity [4]. There are various methods to evaluate the antioxidant capacity in vitro. These methods can be classified as either hydrogen atom transfer (HAT) reaction or electron transfer (ET) reaction. They are widely accepted by many researchers and applied in immense amounts of researches [5].

Hawk tea is one of the most popular herbal teas in the southwest of China. Hawk tea is made from buds or leaves of Litsea coreana var. lanuginose, and this arbor is widely distributed in the mountainous area of south China [6]. Hawk tea infusion with a slight camphor-aromatic smell is free from caffeine and can reduce blood sugar or blood lipid [7]. Due to the different harvest time, Hawk tea can be classified into three types: Hawk bud tea (HB), Hawk primary leaf tea (HP), and Hawk mature leaf tea (HM). Their price fluctuates dramatically due to their yields. In the local markets, the price of $\mathrm{HB}, \mathrm{HP}$, and $\mathrm{HM}$ is about $\$ 50 / \mathrm{kg}, \$ 20 / \mathrm{kg}$, and $\$ 3 / \mathrm{kg}$ [8], respectively. 17 kinds of amino acids and plenty of beneficial mineral elements were found in HP [9], and 32 compounds were identified from the essential oil of HP [10]. However, these researches were all only using HP as the material, and 
the other two types of Hawk tea were overlooked entirely. As a popular traditional beverage, there are more than 30 million drinkers of this beverage [6]. Therefore, it is necessary to investigate the health benefits of Hawk tea infusions.

The objective of this work was to compare the bioactive constituents in three kinds of Hawk tea infusions systematically. In addition, their antioxidant properties (DPPH radical scavenging activity, ferric reducing activity power, and inhibition of erythrocyte hemolysis and LDL oxidation) were also investigated and the correlation between the constituents and antioxidant activity was discussed as well.

\section{Materials and Methods}

2.1. Reagents and Materials. Trolox (6-hydroxy-2,5,7,8tetramethylchroman-2-carboxylic acid), DPPH (1,1diphenyl-2-picrylhydrazyl), TPTZ (1,3,5-tri(2-pyridyl)-2,4,6triazine), and AAPH (2,2' -azobis(2-methylpropionamidine) dihydrochloride) were purchased from Sigma (St. Louis, MO, USA). Ultrapure water was used throughout and obtained from a Milli-Q system.

Hawk teas (Litsea coreana var. lanuginose) were grown in Shangli town $\left(\mathrm{N} 30^{\circ} 08^{\prime} 12.89^{\prime \prime}, \mathrm{E} 103^{\circ} 04^{\prime} 16.57^{\prime \prime}\right)$. The buds, primary leaves, and mature leaves of Hawk tea were harvested in around February, March, and May 2013, respectively. Processed Hawk teas under the same condition were all purchased from the same local retail shop (Yucheng District, Sichuan Province, China) in August 2013. Prior to sample preparation, the teas were ground into homogeneous and fine powder using a pestle and mortar and stored in a desiccator for further analysis.

\subsection{Determination of Bioactive Constituents of Hawk Teas} Infusions. Briefly, $0.5 \mathrm{~g}$ sample was blended with $50 \mathrm{~mL}$ deionized water at $90^{\circ} \mathrm{C}$ and gently agitated for $25 \mathrm{~min}$. After cooling, infusions were centrifuged at $2500 \mathrm{r} / \mathrm{min}$ for $10 \mathrm{~min}$, and then the supernatant was prepared for the following analysis and named Hawk bud tea infusion (HBI), Hawk primary leaf tea infusion (HPI), and Hawk mature leaf tea infusion (HMI), respectively.

Determination of Protein. Content of protein was analyzed according to the Bradford method [11] using bovine serum albumin (BSA) as the standard. Briefly, $10 \mu \mathrm{L}$ sample was added to $5 \mathrm{~mL}$ Coomassie Brilliant Blue G-250 solution $(0.1 \mathrm{mg} / \mathrm{mL})$ in a $10 \mathrm{~mL}$ cuvette. The mixtures were shaken vigorously and incubated in the dark for $5 \mathrm{~min}$. The absorption was measured at $517 \mathrm{~nm}$ using the spectrophotometer (UV-1750, Shimadzu). Values were calculated according to the calibration curve $\left(y=0.0052 x+0.0047, R^{2}=0.996\right)$.

Determination of Vitamin C. Content of vitamin C was determined based upon the quantitative decolouration of 2,6dichlorophenol indophenol [12] using ascorbic acid as the standard. Briefly, $0.5 \mathrm{~mL}$ sample was added to $0.5 \mathrm{~mL} \mathrm{2,6-}$ dichlorophenol indophenol dyeing solution $(0.1 \mathrm{mg} / \mathrm{mL})$ in a $10 \mathrm{~mL}$ cuvette and incubated for $5 \mathrm{~min}$ at room temperature. After that, $5 \mathrm{~mL}$ xylene was added. The mixtures were shaken vigorously for $1 \mathrm{~min}$. The excess dye was extracted by xylene and the absorption was measured at $500 \mathrm{~nm}$ using the spectrophotometer (UV-1750, Shimadzu). Values were calculated according to the calibration curve $(y=0.0053 x+$ $\left.0.0165, R^{2}=0.992\right)$.

Determination of Carbohydrates. Content of carbohydrates was determined by phenol-sulfuric acid colorimetric method [7] using D-glucose as the standard. Briefly, $0.8 \mathrm{~mL}$ sample was added to $0.4 \mathrm{~mL}$ phenol solution $(50 \mathrm{mg} / \mathrm{mL})$ in a $10 \mathrm{~mL}$ cuvette and incubated for $5 \mathrm{~min}$ at room temperature. After that, $2 \mathrm{~mL}$ concentrated sulfuric acid was added. The mixtures were shaken vigorously for $1 \mathrm{~min}$. The absorption was measured at $490 \mathrm{~nm}$ using the spectrophotometer (UV1750, Shimadzu). Values were calculated according to the calibration curve $\left(y=0.004 x+0.001, R^{2}=0.997\right)$.

Determination of Total Flavonoids. Content of total flavonoids (TFC) was determined by the spectrophotometric method [13] using rutin as the standard. Briefly, $0.25 \mathrm{~mL}$ sample was added to $75 \mu \mathrm{L} \mathrm{NaNO}_{2}(50 \mathrm{mg} / \mathrm{mL})$ in a $5 \mathrm{~mL}$ cuvette. After that, $150 \mu \mathrm{L} \mathrm{Al}\left(\mathrm{NO}_{3}\right)_{3}(100 \mathrm{mg} / \mathrm{mL})$ was added and incubated for $5 \mathrm{~min}$ at room temperature. $0.5 \mathrm{~mL} \mathrm{NaOH}(1 \mathrm{~mol} / \mathrm{L})$ and $2.5 \mathrm{~mL}$ deionized water were added and mixed. The absorption was measured at $510 \mathrm{~nm}$ using the spectrophotometer (UV-1750, Shimadzu). Values were calculated according to the calibration curve $\left(y=0.007 x+0.024, R^{2}=0.999\right)$.

Determination of Total Polyphenols. Content of total polyphenols (TPC) was determined by the spectrophotometric method [14] using gallic acid as the standard. Briefly, $50 \mu \mathrm{L}$ sample was added to $0.5 \mathrm{~mL}$ Folin-Ciocalteu solution $(1 \mathrm{~mol} / \mathrm{L})$ in a $5 \mathrm{~mL}$ cuvette and incubated for $5 \mathrm{~min}$ at room temperature. After that, $1.5 \mathrm{~mL} \mathrm{NaNO}_{2}(100 \mathrm{mg} / \mathrm{mL})$ and $1 \mathrm{~mL}$ deionized water were added and mixed. The absorption was measured at $700 \mathrm{~nm}$ using the spectrophotometer (UV1750, Shimadzu). Values were calculated according to the calibration curve $\left(y=0.007 x-0.006, R^{2}=0.998\right)$.

\subsection{Determination of Antioxidant Capacity}

DPPH Radical Scavenging Activity. DPPH radical scavenging activity was evaluated according to the previous report in [15]. Briefly, $1 \mathrm{~mL}$ sample solution was added to $3 \mathrm{~mL} \mathrm{DPPH}$ methanol solution $(0.05 \mathrm{mmol} / \mathrm{L})$ in a $5 \mathrm{~mL}$ cuvette. The mixtures were shaken vigorously and incubated in the dark for $20 \mathrm{~min}$. After that, the reduction of DPPH radical absorption was measured at $517 \mathrm{~nm}$ using the spectrophotometer (UV1750 , Shimadzu). The scavenging activity on DPPH radical was calculated by the following equation:

$$
\begin{aligned}
& \text { DPPH radical scavenging activity (\%) } \\
& \quad=\left[\frac{A_{\mathrm{DPPH}}-A_{\text {sample }}}{A_{\mathrm{DPPH}}}\right] \times 100,
\end{aligned}
$$

where $A_{\mathrm{DPPH}}$ is the absorbance of the DPPH radical solution without sample and $A_{\text {Sample }}$ is the absorbance of the DPPH radical solution with tested samples. 
TABLE 1: Contents of bioactive constituents in three kinds of Hawk tea infusions.

\begin{tabular}{lccccc}
\hline & Protein $(\mathrm{mg} / \mathrm{g})$ & Vc $(\mathrm{mg} / \mathrm{g})$ & Carb. $(\mathrm{mg} / \mathrm{g})$ & TPC $(\mathrm{mg} / \mathrm{g})$ & TFC $(\mathrm{mg} / \mathrm{g})$ \\
\hline HBI & $14.36 \pm 0.43 \mathrm{a}$ & $21.67 \pm 1.32 \mathrm{a}$ & $82.79 \pm 3.98 \mathrm{a}$ & $52.79 \pm 1.35 \mathrm{~b}$ & $24.65 \pm 0.16 \mathrm{a}$ \\
HPI & $3.44 \pm 0.21 \mathrm{c}$ & $19.87 \pm 0.58 \mathrm{a}$ & $69.64 \pm 7.94 \mathrm{~b}$ & $79.01 \pm 1.74 \mathrm{a}$ & $12.59 \pm 0.47 \mathrm{~b}$ \\
HMI & $8.64 \pm 0.41 \mathrm{~b}$ & $3.15 \pm 0.11 \mathrm{~b}$ & $35.97 \pm 5.56 \mathrm{c}$ & $4.22 \pm 0.55 \mathrm{c}$ & $1.25 \pm 0.02 \mathrm{c}$ \\
\hline
\end{tabular}

Different lowercase letters within the same column are significantly different $(P<0.05)$. Vc: vitamin C; Carb.: carbohydrate; TPC: total polyphenols content; TFC: total flavonoids content.

Ferric Reducing Activity Power Assay. Ferric reducing activity power (FRAP) was evaluated according to the previous report in [16] using $\mathrm{FeSO}_{4} \cdot 7 \mathrm{H}_{2} \mathrm{O}$ as the standard. The fresh FRAP reagent was prepared before using, which contains $25 \mathrm{~mL}$ acetate buffer ( $300 \mathrm{mmol} / \mathrm{L}, \mathrm{pH} 3.6), 2.5 \mathrm{~mL}$ TPTZ solutions $(10 \mathrm{mmol} / \mathrm{L}$ in $40 \mathrm{mmol} / \mathrm{L} \mathrm{HCl})$, and $2.5 \mathrm{~mL}$ of $\mathrm{FeCl}_{3} \cdot 6 \mathrm{H}_{2} \mathrm{O}$ solution $(20 \mathrm{mmol} / \mathrm{L})$. The reagent was warmed to $37^{\circ} \mathrm{C}$, and then $500 \mu \mathrm{L}$ was placed in a cuvette and the initiate absorbance was read. $20 \mu \mathrm{L}$ of the sample solutions was added to the cuvette and the absorption was determined at $593 \mathrm{~nm}$ using the spectrophotometer (UV-1750, Shimadzu). Values were calculated according to the calibration curve $(y=$ $0.6786 x-0.0062, R^{2}=0.997$ ).

Erythrocyte hemolysis was based on the previous method in [17] using ascorbic acid as the positive control. Briefly, $200 \mathrm{mmol} / \mathrm{L}$ AAPH was added to $10 \%$ suspension of erythrocytes and then incubated for $2 \mathrm{~h}$ at $37^{\circ} \mathrm{C}$. The absorbances $A$ $(0.15 \mathrm{~mol} / \mathrm{L} \mathrm{NaCl})$ and $B$ (deionized water) of the supernatant were read at $540 \mathrm{~nm}$. The percentage hemolysis was calculated by the equation $(1-A / B) \times 100 \%$; ascorbic acid was used as a positive control.

Low density lipoprotein (LDL) oxidation was based on the previous method in [18] using $\mathrm{Cu}^{2+}$ as the positive control. To monitor conjugated diene, lag time was determined. Briefly, $0.01 \mathrm{~mL} 0.1 \mathrm{mmol} / \mathrm{L} \mathrm{Cu}^{2+}$ (final concentration $5 \mu \mathrm{mol} / \mathrm{L}$ ) was added to the mixture that contained $0.02 \mathrm{~mL}$ LDL $(100 \mu \mathrm{g}$ protein $/ \mathrm{mL})$ and $0.01 \mathrm{~mL}$ sample. To monitor tryptophan fluorescence, the residual tryptophan fluorescence was expressed. Briefly, $0.01 \mathrm{~mL} 0.1 \mathrm{mmol} / \mathrm{L} \mathrm{Cu}^{2+}$ (final concentration $5 \mu \mathrm{mol} / \mathrm{L}$ ) was added to the mixes that contained $0.014 \mathrm{~mL} \mathrm{LDL}(125 \mu \mathrm{g}$ protein $/ \mathrm{mL})$ and $0.02 \mathrm{~mL}$ sample.

2.4. Statistical Analysis. Experiments were carried out in triplicate, and data were reported as means \pm standard deviation (SD) and evaluated by Student's $t$-test. The $P$ values were set at $P<0.05$ to assess the statistical significance.

\section{Results and Discussion}

3.1. Effects of Maturity Degree on Bioactive Constituents of Hawk Tea Infusions. As shown in Table 1, the bioactive constituents of Hawk tea infusions were affected dramatically by the maturity degree of the raw material $(P<0.05)$.

The protein contents ranged from 3.44 to $14.36 \mathrm{mg} / \mathrm{g}$. The highest protein content was found in HBI $(14.36 \mathrm{mg} / \mathrm{g})$, while the lowest protein content was found in HPI $(3.44 \mathrm{mg} / \mathrm{g})$. The vitamin C contents of three kinds of Hawk tea infusions varied from 3.15 to $21.67 \mathrm{mg} / \mathrm{g}$. The highest level of vitamin
C was found in HBI, while the lowest level was in HMI. The highest carbohydrate content was found in HBI $(82.79 \mathrm{mg} / \mathrm{g})$, which was more than twice that in HMI $(35.97 \mathrm{mg} / \mathrm{g})$.

The results showed that tender leaves had more vitamin $\mathrm{C}$ contents than mature leaves. Commonly, the more mature the leaves, the higher the vitamin $\mathrm{C}$ content. When it comes to the infusion, it is the opposite. This phenomenon might be related to the available dissolution rate of vitamin C. Mature leaves had more cellulose and pectin which were the main components of cell wall. In addition, vitamin $\mathrm{C}$ mainly existed in plant cell wall [19]. Vitamin C in tender leaves might be easily released because of its less cellulose and/or pectin, and so were protein and carbohydrate. Another reason might be due to the difference of their water content in fresh material, and in general tender leaves contained much more water than mature leaves.

Polyphenols in tea primarily include flavonoids, phenolic acids, tannins, and lignans [20]. The level of total polyphenols fluctuated dramatically in Hawk tea infusions and ranged from 4.22 to $79.01 \mathrm{mg} / \mathrm{g}$ (Table 1). The highest level of total polyphenols was found in HPI, while the lowest level was in HMI. These results indicated a general trend that young material contained higher level of polyphenols.

Chiu and Lin [21] found that the content of total polyphenols in young leaf was much higher than that in old leaf of Tung-Ting tea. Total polyphenols of the fermented tea whose raw material came from dry season were significantly higher than those from monsoon season [22]. Therefore, the content of total polyphenols may be affected by species, region, climate, and maturity degree. In our results, young leaf infusion (HPI) showed a higher level of total polyphenols than the mature leaf infusion (HMI), but the more tender material infusion (HBI) contained less polyphenols than young leaf infusion (HPI). Since the bud is composed of unexpanded leaves and undeveloped stem, the undeveloped stem may have much less polyphenols than leaf. Therefore, although HB was younger than HP, HBI showed a lower level of polyphenols than HPI.

Flavonoids are the main groups of polyphenols and they are important antioxidants due to their high redox potential [23]. The main groups of flavonoids in Hawk tea are quercetin, quercetin-3-o- $\beta$-D-galactopyranoside, kaempferol-3-o$\beta$-D-glucopyranoside, quercetin-3-o- $\beta$-D-glucopyranoside, and kaempferol-3-o- $\beta$-D-galactopyranoside [24]. Yu and $\mathrm{Gu}$ [9] found that the content of total flavones in Hawk tea was about triple that in green tea. HBI was the richest source of total flavonoids, $24.65 \mathrm{mg} / \mathrm{g}$, while HMI was the lowest, just $1.25 \mathrm{mg} / \mathrm{g}$ (Table 1). The ratio of total flavones to total polyphenols in HBI was very high, which accounted 
TABLE 2: DPPH radical scavenging activities of vitamin C, HMI, HPI, and HBI. Each value is the mean \pm SD.

\begin{tabular}{lccccc}
\hline & \multicolumn{5}{c}{ DPPH radical scavenging activity $(\%)$} \\
Con $^{\mathrm{a}}(\mathrm{mg} / \mathrm{mL})$ & 0.1 & 0.2 & 0.3 & 0.4 & 0.5 \\
\hline HBI & $79.51 \pm 0.61 \mathrm{c}$ & $80.55 \pm 1.50 \mathrm{c}$ & $83.01 \pm 1.03 \mathrm{c}$ & $86.00 \pm 0.71 \mathrm{c}$ & $86.15 \pm 0.92 \mathrm{c}$ \\
HPI & $85.91 \pm 0.88 \mathrm{~b}$ & $87.76 \pm 0.43 \mathrm{~b}$ & $90.01 \pm 0.26 \mathrm{~b}$ & $90.89 \pm 0.17 \mathrm{~b}$ & $91.99 \pm 0.14 \mathrm{~b}$ \\
HMI & $54.93 \pm 0.61 \mathrm{~d}$ & $61.80 \pm 0.43 \mathrm{~d}$ & $66.32 \pm 0.16 \mathrm{~d}$ & $69.45 \pm 0.30 \mathrm{~d}$ & $75.71 \pm 0.98 \mathrm{~d}$ \\
Vitamin C & $96.38 \pm 0.47 \mathrm{a}$ & $96.47 \pm 0.34 \mathrm{a}$ & $96.50 \pm 0.46 \mathrm{a}$ & $96.83 \pm 0.85 \mathrm{a}$ & $97.00 \pm 0.41 \mathrm{a}$ \\
\hline
\end{tabular}

$\mathrm{Con}^{\mathrm{a}}$ : concentration; different letters (a, b, c, and d) show statistical significance $(P<0.05)$.

TABLE 3: FRAP value of HMI, HPI, and HBI. Each value is the mean \pm SD.

\begin{tabular}{lccccc}
\hline & \multicolumn{5}{c}{ FRAP value $(\mathrm{mmol} / \mathrm{L})$} \\
Con $^{\mathrm{a}}(\mathrm{mg} / \mathrm{mL})$ & 0.1 & 0.2 & 0.3 & 0.4 & 0.5 \\
\hline HBI & $0.68 \pm 0.03 \mathrm{~b}$ & $1.02 \pm 0.11 \mathrm{~b}$ & $1.33 \pm 0.02 \mathrm{~b}$ & $1.56 \pm 0.01 \mathrm{~b}$ & $1.95 \pm 0.03 \mathrm{~b}$ \\
HPI & $0.97 \pm 0.04 \mathrm{a}$ & $1.50 \pm 0.02 \mathrm{a}$ & $2.20 \pm 0.16 \mathrm{a}$ & $2.45 \pm 0.16 \mathrm{a}$ & $2.60 \pm 0.08 \mathrm{a}$ \\
HMI & $0.62 \pm 0.02 \mathrm{~b}$ & $0.91 \pm 0.04 \mathrm{~b}$ & $1.23 \pm 0.04 \mathrm{c}$ & $1.49 \pm 0.02 \mathrm{c}$ & $1.71 \pm 0.01 \mathrm{c}$ \\
\hline
\end{tabular}

$\mathrm{Con}^{\mathrm{a}}$ : concentration; different letters $(\mathrm{a}, \mathrm{b}$, and $\mathrm{c})$ show statistical significance $(P<0.05)$.

for almost half of the total polyphenols. The similar trend was also found that young raw material contained more flavonoids than the aged raw material.

\subsection{Effects of Maturity Degree on Antioxidant Activities of Hawk Tea Infusions}

DPPH Radical Scavenging Activity. The results were shown in Table 2; the scavenging effects of Hawk tea infusions were well correlated with the concentration up to $0.5 \mathrm{mg} / \mathrm{mL}$. HPI had the strongest activity, while HMI was the lowest $(P<0.05)$. At $0.5 \mathrm{mg} / \mathrm{mL}$, the scavenging activities of HMI, HPI, and HBI were $75.7 \%, 92.0 \%$, and $86.2 \%$, respectively. So HMI was the weakest electron donor among them. Older raw material showed weaker DPPH free radical scavenging activity. These results are in line with the trend of contents of polyphenols, so $\mathrm{DPPH}$ free radical scavenging activity may be closely related to the polyphenols in Hawk tea.

FRAP Values. Table 3 showed that the reducing power of Hawk tea infusions was positively correlated with the increased concentration up to $0.5 \mathrm{mg} / \mathrm{mL}$. The FRAP values of HPI, HBI, and HMI were $1.9 \mathrm{mmol} / \mathrm{L}, 2.6 \mathrm{mmol} / \mathrm{L}$, and $1.7 \mathrm{mmol} / \mathrm{L}$ at the concentration of $0.5 \mathrm{mg} / \mathrm{mL}$, respectively. The FRAP values of HPI were generally higher than those of HBI and HMI at all tested concentrations, indicating that maturity degree significantly influenced FRAP value of Hawk tea infusions.

Assay for Erythrocyte Hemolysis. Figure 1(a) shows that all samples can inhibit lysis of human erythrocyte. All Hawk tea infusions showed higher ability to inhibit lysis of human erythrocyte than vitamin $\mathrm{C}(200 \mathrm{mmol} / \mathrm{L})$. The inhibition rate of HMI is $83.80 \%$, even though it is the lowest among the Hawk tea infusions. These results indicate that Hawk tea is an excellent potential candidate for inhibiting lysis of human erythrocyte. Zhu et al. [25] reported that the flavonoidrich cocoa played a significant role in protection against human erythrocyte hemolysis in adults and exhibited dosedependent activity.

Inhibition of LDL Oxidation. The antioxidants can delay LDL oxidation, which is characterized by the increase of lag time [26]. The lag time can be obtained from monitoring the formation of conjugated diene in the presence of antioxidants. Among the Hawk tea infusions, HBI had the strongest ability to suppress copper-induced LDL oxidation, which prolonged the time to form the conjugated diene by $36 \%$ comparing with control, and HMI had the weakest ability, which prolonged the time only by $5 \%$ comparing with control (Figure 1(b)). The ability to suppress copper-induced LDL oxidation decreased as the maturity degree of the raw material increased.

Protein oxidation would lead to loss of tryptophan fluorescence, and Figure 1(c) showed the loss of tryptophan fluorescence in LDL. The same with the lag time of LDL to form conjugated diene, all tested samples showed strong ability to inhibit human LDL oxidation, and HBI exhibited stronger ability than HPI and HMI (Figure 1(c)). The results in Figure 1(c) indicate that the activity of suppressing human LDL oxidation decreased with the maturity degree of the raw material increasing.

Lue et al. [27] reported that LDL oxidation was related to the content or species of flavones. HBI showed stronger ability to suppress LDL oxidation than HPI, although it had less content of total flavones than HPI. This result might be due to its high active flavones species or other active constituents.

3.3. Correlation between Polyphenol and Antioxidant Activity of Hawk Tea Infusions. Polyphenols are one of the main bioactive components in natural resources and the correlation between polyphenols and their antioxidant activities was discussed in many reports. Zhang et al. [28] reported a positive correlation between the content of total flavonoids and their antioxidant capacity. Wojdyło et al. [29] showed a similar trend between total polyphenols and their antioxidant capacity. Correlation analysis that quantifies the relationship 


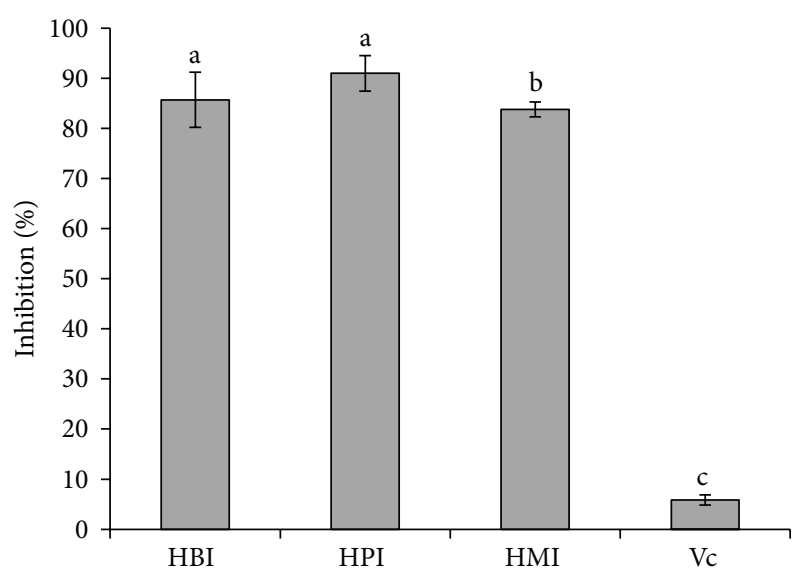

(a)

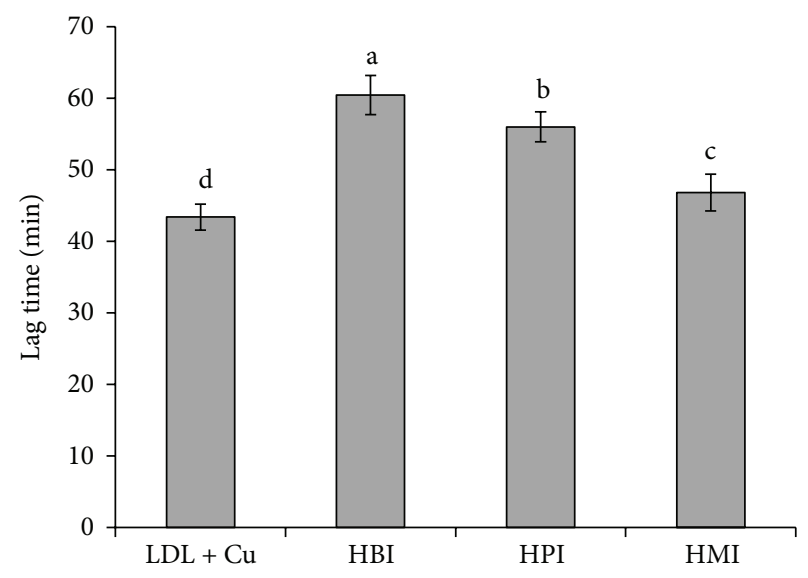

(b)

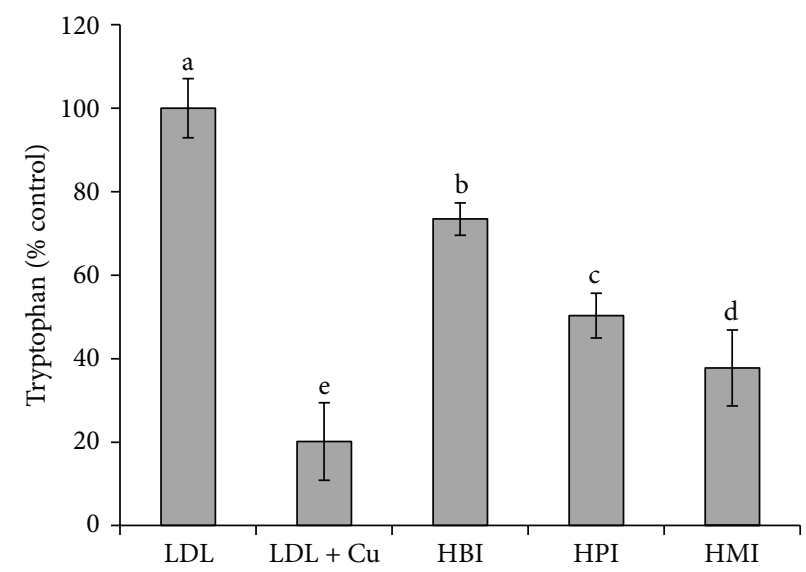

(c)

Figure 1: Effects of Hawk tea infusions on hemolysis of human erythrocytes (a); the lag time for formation of conjugated diene (b); and percentage of residual tryptophan fluorescence in LDL incubated in vitro (c). Each value is the mean \pm SD; different letters (a, b, c, d, and e) show statistical significance $(P<0.05)$.

TABLE 4: Correlation matrix of bioactive components in Hawk tea infusions and their antioxidant capacity.

\begin{tabular}{|c|c|c|c|c|c|c|c|}
\hline & Protein & $\mathrm{Vc}$ & Carbohydrate & TPC & TFC & $\mathrm{DPPH}$ & FRAP \\
\hline Protein & 1 & & & & & & \\
\hline $\mathrm{Vc}$ & 0.1156 & 1 & & & & & \\
\hline Carbohydrate & 0.2986 & 0.9825 & 1 & & & & \\
\hline $\mathrm{TPC}$ & -0.3196 & 0.9042 & 0.8089 & 1 & & & \\
\hline TFC & 0.5390 & 0.8990 & 0.9648 & 0.6259 & 1 & & \\
\hline $\mathrm{DPPH}$ & -0.3286 & 0.9001 & 0.8032 & 0.9823 & 0.6184 & 1 & \\
\hline FRAP & -0.6792 & 0.6505 & 0.4976 & 0.9125 & 0.2521 & 0.9164 & 1 \\
\hline
\end{tabular}

Vc: vitamin C; TPC: total polyphenols content; TFC: total flavonoids content.

between the antioxidants and antioxidant capacity in Hawk tea infusions was measured by correlation coefficient $r$. The results were shown in Table 4.

The results indicated that DPPH radical scavenging activity was strongly correlated with TPC $(r=0.9823)$ and vitamin $C(r=0.9001)$ in Hawk tea. In all tested constituents, polyphenols were mainly responsible for FRAP. This indicated that polyphenols in plant had powerful capacity to reduce $\mathrm{Fe}^{3+}$ to $\mathrm{Fe}^{2+}$. In this study, polyphenols in Hawk tea infusions had high affinity with DPPH radical. The species of polyphenols might be different among the three kinds of Hawk teas and further research is needed.

Hackman et al. [30] demonstrated that there was a close relationship between the DPPH radical scavenging activity 
and polyphenols with low molecular weight in oolong tea. Wojdyło et al. [29] found that the content of total flavonoids was highly positively correlated with DPPH radical scavenging activity in 32 herbs from Poland, which was similar to our results.

Typically, bioactive compounds of plants were produced as secondary metabolites. Primary metabolites, carbohydrates and proteins, were the chemical substances aimed at growth and development. It was reported that peptides [8] and polysaccharide [6] from Hawk tea showed strong antioxidant activity. Therefore, contents of protein and carbohydrate in this work were determined. On the other hand, secondary metabolites, polyphenols and flavonoids, helped plants to increase their overall ability to survive and overcome local challenges by allowing them to interact with their surroundings [31]. It had been reported that bioactive compounds in tea infusion from Forsythia suspensa leaves showed a good antioxidant activity [32], and so were tea samples [33]. The antioxidant activity of bioactive compounds might be related to their structure, which had one or more hydroxyl groups and exhibited complex-molecular-mass polymers [34].

\section{Conclusion}

Bioactive components (protein, carbohydrate, vitamin C, total polyphenols, and total flavonoids) and antioxidant activities (DPPH, FRAP, erythrocyte hemolysis, and LDL oxidation) in Hawk tea infusions were investigated. The results indicated that HPI possessed higher content of total polyphenols, almost $79.01 \mathrm{mg} / \mathrm{g}$, but its total flavonoids, carbohydrates, and proteins were much less than HBI. When it comes to antioxidant activity, HPI exhibited the strongest $\mathrm{DPPH}$ radical scavenging activity and ferric reducing power. Hence, the polyphenols could be the dominant contributors for HPI's high antioxidant activity.

Our results also indicated that the young leaves of Hawk tea had more contents of all bioactive components than the mature leaves. Furthermore, the young leaves showed higher antioxidant activity than the mature leaves. These results indicated that bioactive components and their antioxidant activity were significantly affected by the maturity degree of the raw material.

\section{Conflict of Interests}

The authors declare that there is no conflict of interests regarding the publication of this paper.

\section{Authors' Contribution}

Ming Yuan and Xuejing Jia contributed equally to this work.

\section{Acknowledgment}

This work was supported by the Scientific Research Foundation for Young Scholars of the Education Department of Sichuan Province, China (11ZB054).

\section{References}

[1] I. S. Young and J. V. Woodside, "Antioxidants in health and disease," Journal of Clinical Pathology, vol. 54, no. 3, pp. 176-186, 2001.

[2] P. Deetae, P. Parichanon, P. Trakunleewatthana, C. Chanseetis, and S. Lertsiri, "Antioxidant and anti-glycation properties of Thai herbal teas in comparison with conventional teas," Food Chemistry, vol. 133, no. 3, pp. 953-959, 2012.

[3] H. Aoshima, S. Hirata, and S. Ayabe, "Antioxidative and antihydrogen peroxide activities of various herbal teas," Food Chemistry, vol. 103, no. 2, pp. 617-622, 2007.

[4] I. C. W. Arts and P. C. H. Hollman, "Polyphenols and disease risk in epidemiologic studies," The American Journal of Clinical Nutrition, vol. 81, no. 1, pp. 317-325, 2005.

[5] D. Huang, O. U. Boxin, and R. L. Prior, "The chemistry behind antioxidant capacity assays," Journal of Agricultural and Food Chemistry, vol. 53, no. 6, pp. 1841-1856, 2005.

[6] X. J. Jia, C. B. Ding, S. Yuan et al., "Extraction, purification and characterization of polysaccharides from Hawk tea," Carbohydrate Polymers, vol. 99, no. 1, pp. 319-324, 2014.

[7] X. Jia, L. Dong, Y. Yang, S. Yuan, Z. Zhang, and M. Yuan, "Preliminary structural characterization and antioxidant activities of polysaccharides extracted from Hawk tea (Litsea coreana var. lanuginosa)," Carbohydrate Polymers, vol. 95, no. 1, pp. 195-199, 2013.

[8] X. J. Jia, C. B. Ding, L. H. Dong et al., "Comparison the chemical and functional properties of protein hydrolysates from different mature degree hawk teas," Journal of Food and Nutrition Research, vol. 1, no. 6, pp. 138-144, 2013.

[9] J. P. Yu and L. Q. Gu, "The chemical constituent of laoying Tea from Guizhou," Joural of Plant Resources and Environment, vol. 10 , no. 3, pp. 61-62, 2001.

[10] J. P. Yu, L. Q. Gu, and S. X. Ren, "Study on the essential oil compositions of the leaves of Litsea coreana from Guizhou," Food Science, vol. 7, no. 22, pp. 63-64, 2001.

[11] M. M. Bradford, "A rapid and sensitive method for the quantitation of microgram quantities of protein utilizing the principle of protein dye binding," Analytical Biochemistry, vol. 72, no. 1-2, pp. 248-254, 1976.

[12] B. Rodríguez Galdón, D. Ríos Mesa, E. M. Rodríguez Rodríguez, and C. Díaz Romero, "Influence of the cultivar on the organic acid and sugar composition of potatoes," Journal of the Science of Food and Agriculture, vol. 90, no. 13, pp. 23012309, 2010.

[13] C. H. Chang, C. L. Hsieh, H. E. Wang, C. C. Peng, C. C. Chyau, and R. Y. Peng, "Unique bioactive polyphenolic profile of guava (Psidium guajava) budding leaf tea is related to plant biochemistry of budding leaves in early dawn," Journal of the Science of Food and Agriculture, vol. 93, no. 4, pp. 944-954, 2013.

[14] N. Turkmen, F. Sari, and Y. S. Velioglu, "Effects of extraction solvents on concentration and antioxidant activity of black and black mate tea polyphenols determined by ferrous tartrate and Folin-Ciocalteu methods," Food Chemistry, vol. 99, no. 4, pp. 835-841, 2006.

[15] R. T. Lochmann, S. Islam, H. Phillips, Z. Adam, and J. Everette, "Effects of dietary sweet potato leaf meal on the growth, non-specific immune responses, total phenols and antioxidant capacity in channel catfish (Ictalurus punctatus)," Journal of the Science of Food and Agriculture, vol. 93, no. 6, pp. 1365-1369, 2013. 
[16] T. Frank, G. Netzel, D. R. Kammerer et al., "Consumption of Hibiscus sabdariffa L. aqueous extract and its impact on systemic antioxidant potential in healthy subjects," Journal of the Science of Food and Agriculture, vol. 92, no. 10, pp. 22072218, 2012.

[17] T. B. Ng, F. Liu, and Z. T. Wang, "Antioxidative activity of natural products from plants," Life Sciences, vol. 66, no. 8, pp. 709-723, 2000.

[18] E. Venditti, T. Bacchetti, L. Tiano, P. Carloni, L. Greci, and E. Damiani, "Hot vs. cold water steeping of different teas: do they affect antioxidant activity?" Food Chemistry, vol. 119, no. 4, pp. 1597-1604, 2010.

[19] P. J. P. Espitia, W. Du, R. D. J. Avena-Bustillos, N. D. F. F. Soares, and T. H. McHugh, "Edible films from pectin: Physical-mechanical and antimicrobial properties-a review," Food Hydrocolloids, vol. 35, pp. 287-296, 2014.

[20] I. Ignat, I. Volf, and V. I. Popa, "A critical review of methods for characterisation of polyphenolic compounds in fruits and vegetables," Food Chemistry, vol. 126, no. 4, pp. 1821-1835, 2011.

[21] F. Chiu and J. Lin, "HPLC analysis of naturally occurring methylated catechins, $3 / /$ - and $4 / I$-methyl-epigallocatechin gallate, in various fresh tea leaves and commercial teas and their potent inhibitory effects on inducible nitric oxide synthase in macrophages," Journal of Agricultural and Food Chemistry, vol. 53, no. 18, pp. 7035-7042, 2005.

[22] S. Jayasekera, A. L. Molan, M. Garg, and P. J. Moughan, "Variation in antioxidant potential and total polyphenol content of fresh and fully-fermented Sri Lankan tea," Food Chemistry, vol. 125, no. 2, pp. 536-541, 2011.

[23] R. Tsao and R. Yang, "Optimization of a new mobile phase to know the complex and real polyphenolic composition: towards a total phenolic index using high-performance liquid chromatography," Journal of Chromatography A, vol. 1018, no. 1, pp. 29-40, 2003.

[24] Y. P. Chen, W. M. Cheng, and J. Li, "Analyse on the chemical constituents from flavonoids of Litsea coreana L.," Acta Universitatis Medicinalis Anhui, vol. 43, no. 1, pp. 65-67, 2008.

[25] Q. Y. Zhu, D. D. Schramm, H. B. Gross et al., "Influence of cocoa flavanols and procyanidins on free radical-induced human erythrocyte hemolysis," Clinical and Developmental Immunology, vol. 12, no. 1, pp. 27-34, 2005.

[26] B. Zieden, D. M. Wuttge, B. E. Karlberg, and A. G. Olsson, "Effects of in vitro addition of captopril on copper-induced low density lipoprotein oxidation," British Journal of Clinical Pharmacology, vol. 39, no. 2, pp. 201-203, 1995.

[27] B. Lue, N. S. Nielsen, C. Jacobsen, L. Hellgren, Z. Guo, and $\mathrm{X}$. $\mathrm{Xu}$, "Antioxidant properties of modified rutin esters by $\mathrm{DPPH}$, reducing power, iron chelation and human low density lipoprotein assays," Food Chemistry, vol. 123, no. 2, pp. 221-230, 2010.

[28] G. Zhang, L. He, and M. Hu, "Optimized ultrasonic-assisted extraction of flavonoids from Prunella vulgaris L. and evaluation of antioxidant activities in vitro," Innovative Food Science and Emerging Technologies, vol. 12, no. 1, pp. 18-25, 2011.

[29] A. Wojdyło, J. Oszmiański, and R. Czemerys, "Antioxidant activity and phenolic compounds in 32 selected herbs," Food Chemistry, vol. 105, no. 3, pp. 940-949, 2007.

[30] R. M. Hackman, Q. Y. Zhu, J. L. Ensunsa, R. R. Holt, and C. L. Keen, "Antioxidative activities of oolong tea," Journal of Agricultural and Food Chemistry, vol. 50, no. 23, pp. 6929-6934, 2002.
[31] J. Azmir, I. S. M. Zaidul, M. M. Rahman et al., "Techniques for extraction of bioactive compounds from plant materials: a review," Journal of Food Engineering, vol. 117, no. 4, pp. 426-436, 2013.

[32] J. Jiao, Q. Gai, M. Luo et al., "Comparison of main bioactive compounds in tea infusions with different seasonal Forsythia suspensa leaves by liquid chromatography-tandem mass spectrometry and evaluation of antioxidant activity," Food Research International, vol. 53, no. 2, pp. 857-863, 2013.

[33] Y. t. Zhang, Q. Li, H. Xing et al., "Evaluation of antioxidant activity of ten compounds in different tea samples by means of an on-line HPLC-DPPH assay," Food Research International, vol. 53, no. 2, pp. 847-856, 2013.

[34] N. Balasundram, K. Sundram, and S. Samman, "Phenolic compounds in plants and agri-industrial by-products: antioxidant activity, occurrence, and potential uses," Food Chemistry, vol. 99, no. 1, pp. 191-203, 2006. 


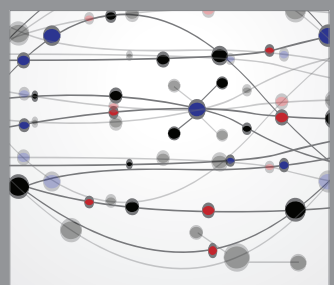

The Scientific World Journal
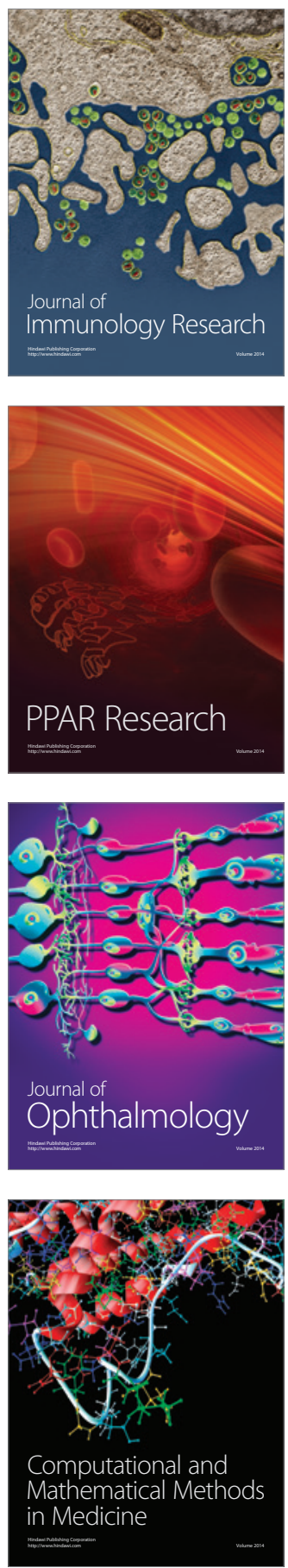

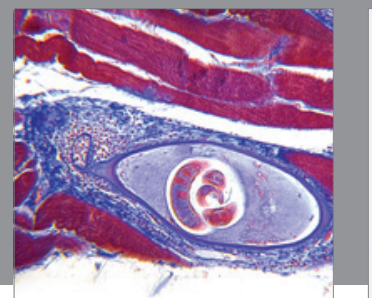

Gastroenterology

Research and Practice
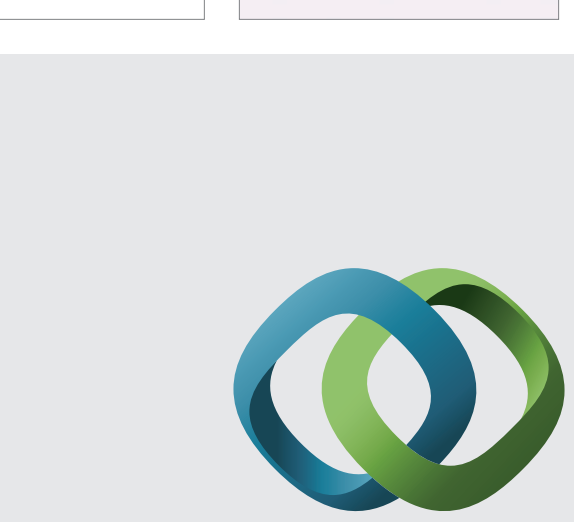

\section{Hindawi}

Submit your manuscripts at

http://www.hindawi.com
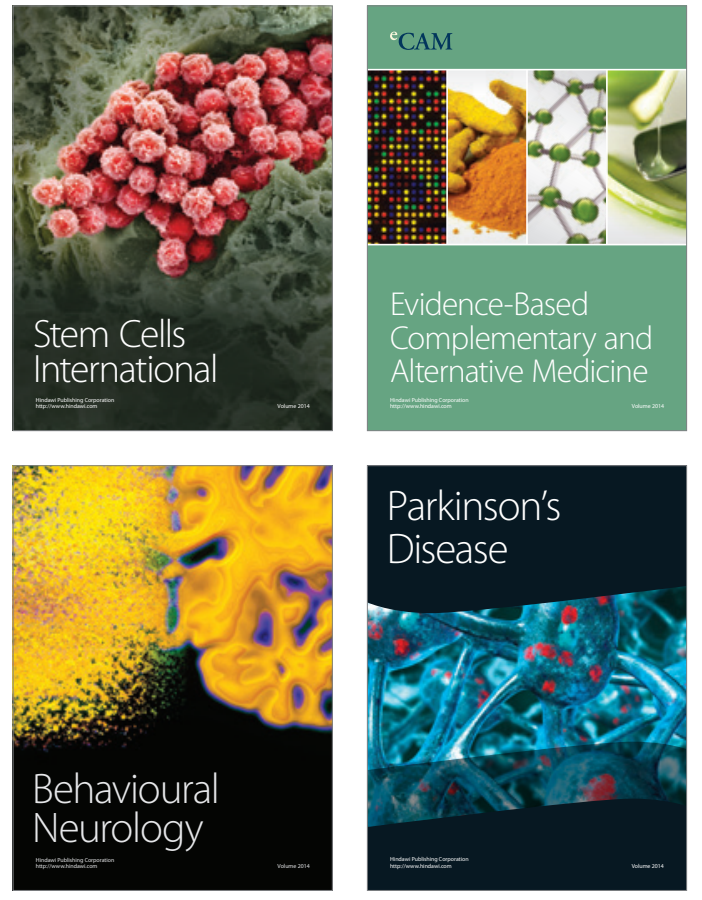
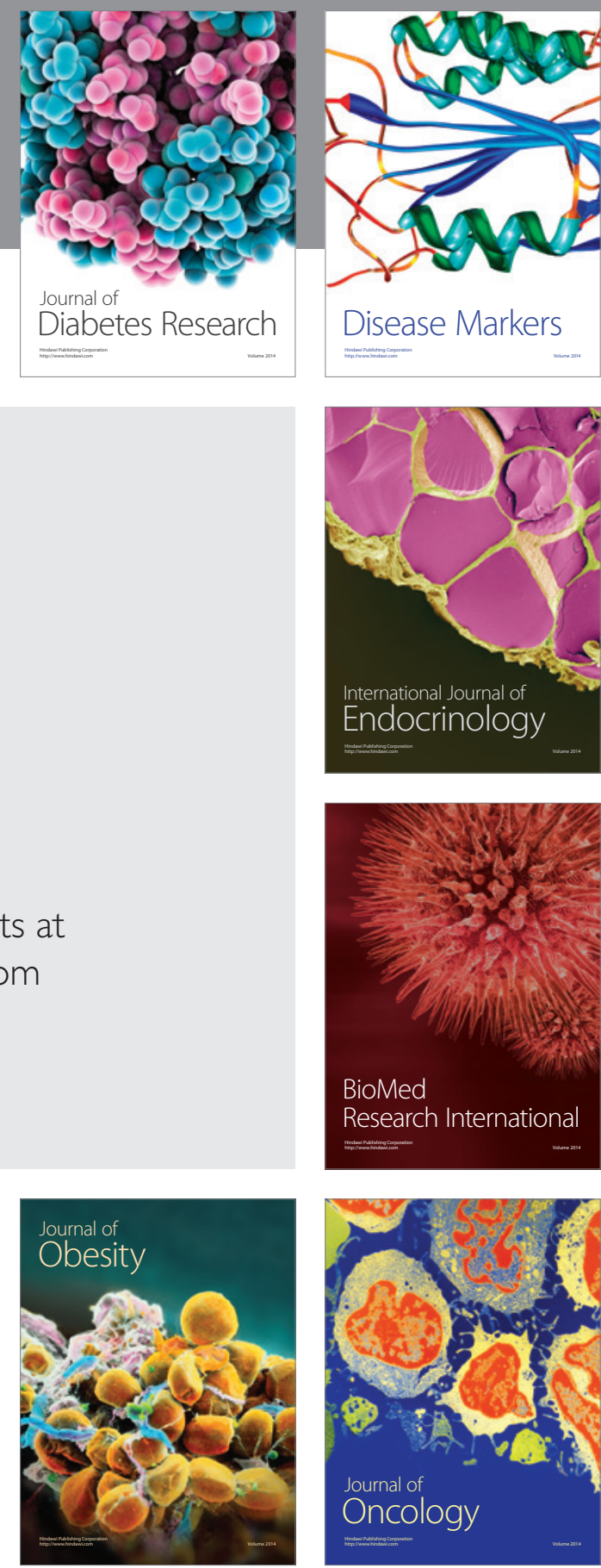

Disease Markers
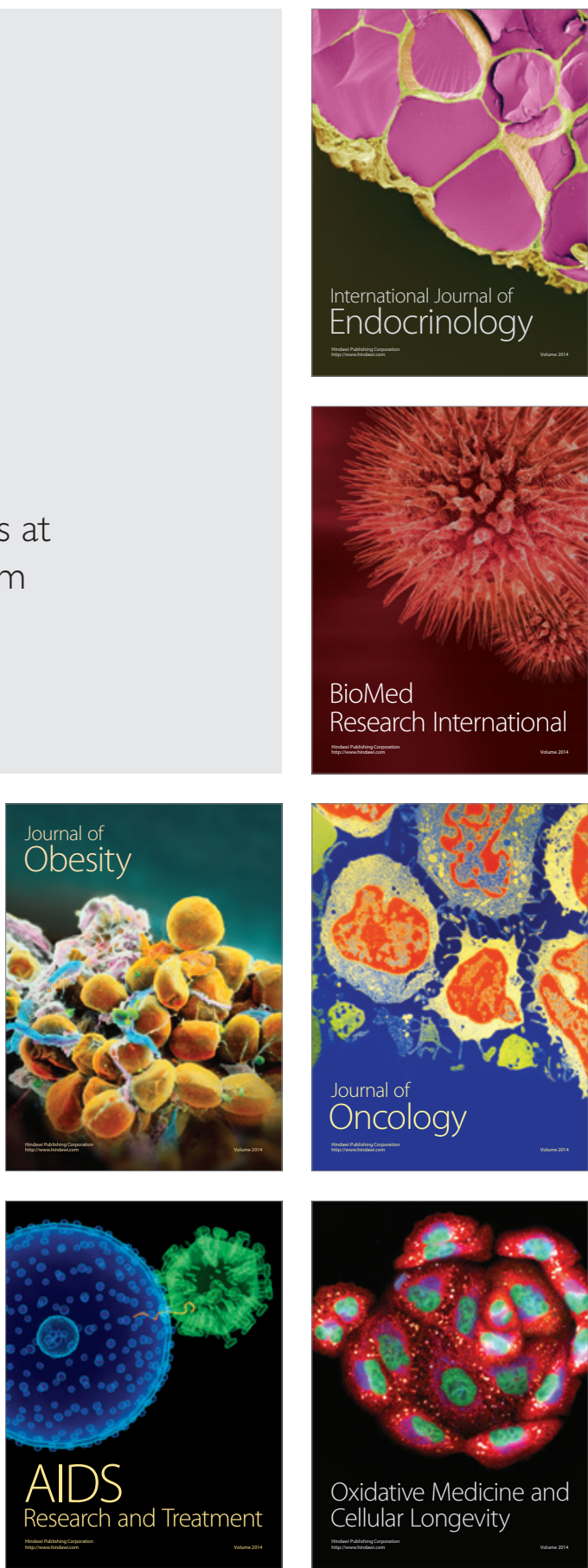